\title{
LA DECISIÓN MARCO SOBRE LA ORDEN EUROPEA DE DETENCIÓN Y ENTREGA REINTERPRETADA POR EL TRIBUNAL DE JUSTICIA DE LA UNIÓN EUROPEA
}

\author{
The framework decision on the European arrest \\ Warrant reinterpreted by the Court of Justice \\ of the European Union
}

SUSANA RUIZ TARRÍAS

Universidad de Granada

starrias@ugr.es

Cómo citar/Citation

Ruiz Tarrias, S. (2019).

La decisión marco sobre la orden europea de detención y entrega reinterpretada por el Tribunal de Justicia de la Unión Europea. Anuario Iberoamericano de Justicia Constitucional, 23(2), 459-490. doi: https://doi.org/10.18042/cepc/aiic.23.14

Resumen

Tradicionalmente se ha considerado que el principio de reconocimiento mutuo constituye la piedra angular en la que descansa la regulación de la orden europea de detención y entrega regulada a través de la Decisión Marco 2002/584/JAI. Sin embargo, la pervivencia de un acto jurídico de esta naturaleza en el contexto del Tratado de Lisboa pone de manifiesto las carencias en la armonización de las regulaciones penales de los Estados miembros, así como la prolongación de la problemática relativa a las decisiones marco y, en particular, respecto de la decisión marco reguladora de la OEDE. Recientemente, el Tribunal de Justicia de la Unión Europea ha articulado a través de su jurisprudencia el denominado test Aranyosi, aplicable en circunstancias excepcionales, a resultas del cual la autoridad jurisdiccional de ejecución puede abstenerse de dar cumplimiento a una OEDE. 


\section{Palabras clave}

Decisiones marco; reconocimiento mutuo; orden europea de detención y entrega; Tribunal de Justicia; test Aranyosi.

\section{Abstract}

Mutual recognition has been traditionally considered the cornerstone of the European Arrest Warrant that is covered by the Framework Decision 2002/584/JHA. Nevertheless, the continued existence of such legal act under the Lisbon Treaty highlights the gaps of the harmonization into the criminal law of the Member States, as well as the extension of the problems affecting Framework Decisions and, in particular, Framework Decision on EAW over time. Recently, the caselaw of the European Court of Justice has articulated the so called Aranyosi test. Applicable under exceptional circumstances the Aranyosi test can empower the abstention by the judicial authority of execution in completion of an EAW.

\section{Keywords}

Framework Decision; mutual recognition; European Arrest Warrant; European Court of Justice; test Aranyosi. 


\section{SUMARIO}

I. INTRODUCCIÓN. II. EL PRINCIPIO DE RECONOCIMIENTO MUTUO COMO PIEDRA ANGULAR DE LA COOPERACIÓN JUDICIAL EN MATERIA PENAL. III. LA PROBLEMÁTICA DE LAS DECISIONES MARCO EN EL ORDENAMIENTO JURÍDICO DE LA UNIÓN EUROPEA: 1. El cuestionamiento de los efectos jurídicos de las decisiones marco como actos jurídicos del derecho de la UE. 2. Las dudas de carácter formal y material relativas a la decisión marco sobre la orden europea de detención y entrega. IV. LA ORDEN EUROPEA DE DETENCIÓN Y ENTREGA COMO SISTEMA DE LIBRE CIRCULACIÓN DE RESOLUCIONES JUDICIALES EN MATERIA PENAL: 1. La obligación de ejecutar la orden europea de detención y entrega y sus excepciones «tasadas». 2. La Resolución de 15 de diciembre de 2015 del Tribunal Constitucional Federal alemán como quiebra del sistema. V. LA RUPTURA EXCEPCIONAL DEL PRINCIPIO DE CONFIANZA RECÍPROCA Y LA ARTICULACIÓN DEL TEST ARANYOSI. VI. CONCLUSIONES. BIBLIOGRAFIA.

\section{INTRODUCCIÓN}

En su artículo «Mutual Recognition and Criminal Law in the European Union: Has the Council got it wrong?», S. Peers se preguntaba, habida cuenta de la amplia actividad desarrollada por el Consejo de Europa, por qué la Unión Europea debería involucrarse en el aspecto de la cooperación penal.

Según afirmaba, los Estados miembros lo deseaban así, bien para poder «complementar ampliamente» los convenios del Consejo de Europa, reduciendo, por ejemplo, el número de excepciones a las reglas en su condición de Estados miembros de la Unión Europea, o bien para encontrar «rutas alternativas» con las que alcanzar los mismos objetivos cuando las medidas de dichos convenios no atrajeran muchas ratificaciones (Peers, 2004: 7).

Sin embargo, al mismo tiempo se reconocía por todos la especial sensibilidad de la cooperación en materia penal respecto de la soberanía de los Estados miembros.

De hecho, a lo largo del tiempo la Unión Europea se ha movido entre dos «paradigmas». De un lado, la «armonización total» adoptada en los primeros momentos a través de directivas exhaustivas que no dejaba margen a 
la acción de los Estados miembros, y, de otro, la sustitución posterior de este criterio por la «mínima armonización» a través del principio de reconocimiento mutuo como «método de integración negativa» (Mancano, 2018: 75-76), donde cabe situar a la Decisión Marco 2002/584/JAI, relativa a la orden de detención europea y a los procedimientos de entrega entre Estados miembros (en adelante, OEDE) ${ }^{1}$.

Articulada inicialmente en el marco del tercer pilar del derecho originario de la Unión Europea, y, en consecuencia, sobre la base del principio de intergubernamentalidad, el principio de reconocimiento mutuo de las resoluciones judiciales en materia penal entre los Estados miembros constituye la piedra angular sobre la que descansa la OEDE.

No obstante, el cuestionamiento de la propia eficacia jurídica de las decisiones marco (abordada por el Tribunal de Justicia en la Sentencia de 16 de junio de 2005, Pupino), de la idoneidad y compatibilidad con el ordenamiento de la Unión Europea de la propia Decisión Marco 2002/584/JAI (sobre la que se pronunció el Tribunal de Justicia en la Sentencia de 3 de mayo de 2007, Advocaten voor de Wereld VZW), y la inicial declaración de inconstitucionalidad de la normativa de implementación de esta decisión marco por los tribunales constitucionales de Polonia, Alemania y Chipre mediante distintos pronunciamientos dictados en 2005 son algunos de los hitos destacados que muestran la procelosa vida de la OEDE.

Unas dificultades que a lo largo del tiempo han condicionado la aplicación de la OEDE como consecuencia, de un lado, de la carencia de una mínima armonización o aproximación previa de la regulación penal de los Estados miembros, y, de otro, de la ausencia, en términos similares a los de las directivas, de una monitorización por la Comisión Europea de la implementación de estos específicos actos jurídicos del derecho de la UE en los respectivos ordenamientos de los Estados miembros.

Tales insuficiencias fueron puestas de manifiesto con posterioridad a la entrada en vigor del Tratado de Lisboa por Viviane Reding (vicepresidenta de la Comisión Europea) en su conferencia «El futuro de la Justicia Penal Europea bajo el Tratado de Lisboa», pronunciada en la European Law Academy el 12 de marzo de 2010, donde anunciaba la «determinación» de la nueva Comisión para crear una Europa «fuerte» en materia de justicia.

Al mismo tiempo, reconocía que «en el pasado y hasta la actualidad», la UE ha intentado construir el ámbito de la Justicia penal Europea «con una mano atada a su espalda», tratando de adoptar reglas comunes en el tercer pilar. Un ámbito en el que, afirmaba, los Parlamentos y los tribunales tienen

1 DOCE L190/1, de 18-7-2002. 
poco que decir, y donde la regla de la unanimidad de los Gobiernos de la UE frecuentemente ha propiciado un enfoque del «mínimo común denominador», de ahí que el resultado fuera, según estimaba, que habían construido una casa "con solo tres paredes».

El punto de partida seguía siendo, en su opinión, el principio de reconocimiento mutuo de las decisiones judiciales entre los Estados miembros como piedra angular. Sin embargo, a su juicio, la confianza recíproca, que existe o que se desarrolla naturalmente, "no puede establecerse por decreto" (Reding, 2010: 2-3), admitiendo, de este modo, las limitaciones de la Unión Europea para profundizar en la regulación jurídica de la OEDE en el contexto de la supranacionalidad,

De hecho, la propia Decisión Marco 2002/584/JAI, modificada con anterioridad a la entrada en vigor del Tratado de Lisboa por la Decisión Marco 2009/299/JAI del Consejo, de 26 de febrero ${ }^{2}$, permanece actualmente en vigor gracias a la previsión contenida en el art. 9 del Protocolo 36 del Tratado de Lisboa (sobre las disposiciones transitorias), a pesar de no constituir un acto jurídico apto para el ejercicio de las competencias de la Unión según el art. 288 TFUE $^{3}$.

Así, como un iceberg de la intergubernamentalidad flotando a la deriva en la singular despilarización llevada a cabo por el Tratado de Lisboa, la aplicación de la Decisión Marco 2002/584/JAI ha planteado en los últimos años nuevos desafíos a los que el Tribunal de Justicia, con mayor o menor acierto, ha tenido que dar respuesta.

En este contexto cabe situar los pronunciamientos del Tribunal de Justicia sobre la decisión marco relativa a la orden europea de detención y entrega en los asuntos Aranyosi-Căldăraru (Sentencia de 5 de abril de 2016) y LM (Sentencia de 25 de julio de 2018), aplicando una nueva línea interpretativa en la que, por razones excepcionales relacionadas con el cuestionamiento del respeto a determinados derechos fundamentales por parte del Estado miembro emisor que implican la ruptura del principio de confianza recíproca, habilita a la autoridad jurisdiccional de ejecución para abstenerse de dar trámite a la orden europea de detención y entrega.

DOUE L 81/24, de 27-3-2009.

3 En efecto, como resulta conocido, el art. 288 TFUE enuncia como actos jurídicos aptos para el ejercicio de las competencias de la Unión el reglamento, la directiva, la decisión y las recomendaciones y los dictámenes, si bien estos dos últimos carecen de fuerza vinculante. 


\section{EL PRINCIPIO DE RECONOCIMIENTO MUTUO COMO PIEDRA ANGULAR DE LA COOPERACIÓN JUDICIAL EN MATERIA PENAL}

Como resulta conocido, el Tratado de Maastricht (1992) configuró la Unión Europea sobre la base de tres pilares, el tercero de ellos constituido por la cooperación en los ámbitos de la Justicia y de los asuntos de interior (JAI), concebido como ámbito de actuación basado en el método intergubernamental.

En esta genérica regulación inicial, la cooperación judicial en materia penal es referenciada como un ámbito de interés y no como un núcleo competencial en el que los Estados miembros se «informarán» y "consultarán» mutuamente al objeto de coordinar su acción a través de sus respectivas Administraciones (art. K.3.1).

Al mismo tiempo, se reconoce la competencia del Tribunal de Justicia de la UE respecto del control de los "Convenios» celebrados por el Consejo de la Comunidad Europea en los ámbitos de Justicia y asuntos de interior, pero respecto de otros actos jurídicos — como las decisiones marco-, susceptibles de ser adoptados en el ámbito del tercer pilar ${ }^{4}$.

Esta primera regulación del tercer pilar en el derecho originario no contribuyó suficientemente a alcanzar los objetivos propuestos por la UE, como reconocía la Comisión europea en su Dictamen (COM[96] 90 final) de 28 de febrero de 1996: "Reforzar la Unión y preparar la ampliación». Por ello, proponía afrontar las insuficiencias del tratado en los ámbitos de la Justicia y de los asuntos de interior y, más concretamente, su "falta de eficacia» y la «ausencia de control democrático y judicial», formulando «objetivos claros e instrumentos y métodos apropiados» ${ }^{5}$.

4 No obstante, en la práctica, el Tribunal de Justicia se pronunció en relación con la adopción de la "Acción Común» de la Unión, de 4 de marzo de 1996, sobre el régimen de tránsito aeroportuario, adoptada por el Consejo sobre la base del art. K.3.2.b) del Tratado de Maastricht (perteneciente al Tercer Pilar), al considerar la Comisión que dicha regulación debía haberse adoptado de conformidad con los apartados 1 y 3 del art. 100C (perteneciente al primer pilar). Véase STJUE de 12 de mayo de 1998, Comisión de las Comunidades Europeas c. Consejo, Asunto C-170/96, y el comentario de dicho pronunciamiento de Kuijper (2004).

5 Dicho dictamen reconocía que en relación con el espacio de libertad y seguridad, hasta el momento, la Unión había abordado los problemas utilizando «métodos y medios ampliamente superados», en tanto que, afirmaba, ni la acción ni la posición común, cuyos efectos jurídicos resultan "poco claros», ni el convenio internacional clásico, cuya entrada en vigor es «aleatoria y tardía», constituyen instrumentos adaptados a 
Con la aprobación del Tratado de Ámsterdam (1997), la cooperación policial y judicial permaneció en el tercer pilar y, en consecuencia, sujetas al método intergubernamental, aunque el Tratado de Ámsterdam resulta sumamente innovador al expresar el deseo de armonizar las legislaciones nacionales de los Estados miembros en materia penal (Pollicino, 2008: 1317).

A tales efectos, el Tratado de Ámsterdam atribuye al Consejo, a iniciativa de cualquier Estado miembro o la Comisión, y previa consulta al Parlamento Europeo, la facultad para adoptar, entre otros actos jurídicos, «decisiones marco» sin efecto directo, con el fin de aproximar las normas legales y reglamentarias de los Estados miembros, quedando estos obligados al cumplimiento del resultado, pero disponiendo de capacidad de elección respecto de la forma y los medios (art. K.6.2).

Estos actos jurídicos quedan sujetos a una modalidad de control diferente por parte del Tribunal de Justicia. En concreto, su competencia directa de enjuiciamiento se reconoce, con carácter prejudicial, respecto de la validez e interpretación de las «decisiones marco» y de las «decisiones», y sobre la interpretación de los «convenios», así como sobre la validez e interpretación de las «medidas de aplicación» (art. K.7.1) ${ }^{6}$.

Además, se dispone que la competencia prejudicial del Tribunal de Justicia en relación con tales actos jurídicos debe ser aceptada expresamente por los Estados miembros mediante la formulación de declaraciones ad hoc (art. K.7.2), debiendo optar, en caso de formular dicha declaración, entre dos modalidades de reconocimiento (art. K.7.3) ${ }^{7}$.

estas materias, debiendo optarse por instrumentos jurídicos más eficaces que además incluyan su control por el Tribunal de Justicia (ibid.: 6-7).

6 El Tribunal de Justicia había reconocido en la Sentencia de 15 de marzo de 2005, España c. Eurojust, Asunto C-160/03, que su competencia en materia de cooperación policial y judicial en materia penal se rige exclusivamente por lo dispuesto en el art. 35 del Tratado UE (art. K.7 Tratado de Ámsterdam) (párr. 38). Sin embargo, en la Sentencia de 27 de febrero de 2007, Segi, Asunto C-355/04 P, estima que, en aras de "garantizar el respeto al Derecho y aplicar el Tratado", sería contrario a la consecución de dicho objetivo interpretar restrictivamente el art. 35.1 del TUE (art. K.7 Tratado de Ámsterdam), por lo que admite la posibilidad de someter con carácter prejudicial «cualquier asunto relativo a disposiciones adoptadas por el Consejo, con independencia de su naturaleza y de su forma, dirigidas a producir efectos jurídicos frente a terceros» (párr. 53).

7 En la disposición adicional única de la Ley Orgánica 9/1998, de 16 de diciembre, por la que se autoriza la ratificación por España del Tratado de Ámsterdam, aparece la declaración ad hoc del Reino de España aceptando la competencia prejudicial del 
Desde tales premisas, el Consejo Europeo de Tampere (15-16 de octubre de 1999) dedicó especial atención a la construcción de un «auténtico espacio europeo de justicia» bajo la premisa de un mejor reconocimiento mutuo de las resoluciones judiciales y la necesidad de una aproximación de las legislaciones.

Además, haciendo «suyo» el principio del reconocimiento mutuo como piedra angular de la cooperación en materia civil y penal en la Unión, considera que el procedimiento formal de extradición entre los Estados miembros en el caso de personas condenadas por sentencia firme que eluden la Justicia debe sustituirse por el simple traslado de dichas personas a través de «procedimientos acelerados de extradición» respetando el principio de juicio justo.

Un principio de reconocimiento mutuo ${ }^{8}$ que, según reconocen las Conclusiones de la Presidencia del Consejo Europeo de Tampere, debe aplicarse

Tribunal de Justicia de la UE en relación con el artículo K.7, párrafos 2 y 3 del Tratado de la Unión Europea (BOE, núm. 301, de 17 de diciembre de 1998).

A diferencia de las declaraciones formuladas coetáneamente por el resto de los Estados miembros aceptando la competencia prejudicial del Tribunal de Justicia en los términos más amplios previstos en la letra b) del apartado 3 del art. K.7 del Tratado de Ámsterdam (véase la información relativa a la fecha de entrada en vigor del Tratado de Ámsterdam [DOCE L 114/56, de 1-5-1999]), la declaración formulada por el Reino de España opta por asumir la competencia prejudicial del Tribunal de Justicia en los términos más restrictivos (previstos en la letra a), habilitando exclusivamente a los órganos jurisdiccionales nacionales cuyas decisiones no sean susceptibles de ulterior recurso judicial de derecho interno para promover el reenvío prejudicial.

El principio de reconocimiento mutuo nunca ha sido definido en el derecho originario europeo, aunque puede interpretarse, según la Comunicación sobre reconocimiento mutuo de resoluciones firmes en materia penal, de la Comisión al Consejo y al Parlamento Europeo (COM[2000] 495 final), de 26 de julio de 2000 , como «un principio que se suele entender basado en la idea de que mientras un Estado puede no tratar cierta materia de igual o similar modo que otro Estado, los resultados serán tales que se aceptarán como equivalentes a las decisiones del propio Estado. La confianza mutua es un elemento importante; no sólo confianza en la adecuación de las normas de los socios, sino también en que dichas normas se aplican correctamente».

En consecuencia, estrechamente conectado a la confianza recíproca, en todas las materias y variantes de su aplicación en la Unión Europea, el principio de reconocimiento mutuo implica la "presunción refutable» o iuris tantum de que los Estados miembros respetan los derechos fundamentales (Mancano, 2018: 78). En concreto, suele ser común admitir que el principio de reconocimiento mutuo en materia penal proviene de la regulación del mercado interior (Klimek, 2015: 70), donde fue introducido por el Tribunal de Justicia en el caso conocido como Cassis de Dijon (Sentencia de 20 de febrero de 1979, Rewe c. Bundesmonopolverwaltung für Branntwein, Asunto 120/78). 
a las «sentencias» y a otras «resoluciones» de las autoridades judiciales en materia penal (párr. 33), incluidos los «autos» anteriores al juicio, especialmente aquellos que "permiten a las autoridades competentes actuar con celeridad en la obtención de pruebas y embargo de bienes», estimando también que las pruebas obtenidas legalmente por las autoridades de un Estado miembro «deberán ser admisibles» ante los tribunales de otros Estados miembros, teniendo en cuenta la normativa aplicada en ellos (párrs. 35-36).

En este contexto cabe situar la adopción, el 13 de junio de 2002, por el Consejo de la Unión Europea, de la que, a día de hoy, continúa siendo la norma básica reguladora de la OEDE, la Decisión Marco 2002/584/JAI, de 13 de junio, cuya entrada en vigor tuvo lugar el 1 de enero de 2004, posteriormente modificada por la Decisión Marco 2009/299/JAI del Consejo, de 26 de febrero, que incorpora un art. 4 bis; suprime el apartado 1 del art. 5, y modifica el anexo, con el fin de reforzar los derechos procesales de las personas y propiciar la aplicación del principio de reconocimiento mutuo de las resoluciones dictadas a raíz de juicios celebrados sin comparecencia del imputado (in absentia).

Desde entonces, el principio de reconocimiento mutuo se ha mantenido como piedra angular de la cooperación en materia civil y penal en la Unión, incluso en el marco de la «despilarización» que efectuaba el proyecto de Tratado Constitucional Europeo (Spaventa, 2007: 15) y, posteriormente, en el Tratado de Lisboa ${ }^{9}$. Este último regula la cooperación judicial en materia penal en el capítulo IV del título V del TFUE, bajo la premisa de que se basará en el principio de reconocimiento mutuo de las sentencias y resoluciones judiciales (art. 82.1 TFUE), sin perjuicio del ejercicio de las responsabilidades que incumben a los Estados miembros en lo referente al mantenimiento del orden público y la salvaguarda de la seguridad interior (art. 72 TFUE).

Sin embargo, la entrada en vigor del Tratado de Lisboa no conlleva, automáticamente, la plena comunitarización del tercer pilar, en tanto que el Protocolo 36 del Tratado de Lisboa (sobre las disposiciones transitorias) prevé en su art. 9 el mantenimiento de los efectos jurídicos de los actos de las instituciones, órganos u organismos de la Unión adoptados con anterioridad a la entrada en vigor del Tratado de Lisboa en el marco de los títulos V y VI del TUE mientras no sean derogados, anulados o modificados en aplicación de los tratados, circunstancia que concurre en la Decisión Marco 2002/584/JAI.

De este modo, la pervivencia en el ordenamiento jurídico de la Unión Europea de esta regulación —modificada según la Decisión Marco 2009/299/ JAI- no solo conlleva la subsistencia hasta nuestros días del sustrato dialéctico

9 En este sentido, Grasso (2015) estima que el Tratado de Lisboa establece las bases de lo que se podría considerar un «Derecho Penal europeo». 
por el que transitaron en su momento los aspectos jurídicamente controvertidos de este acto jurídico de la UE, sino, también, la continuidad de las propias carencias de un sistema fundado, todavía hoy, en la regla del mínimo común denominador propia del intergubernamentalismo, y donde el control del Tribunal de Justicia «sigue presentando evidentes carencias» (Alonso García, 2012: 392).

En efecto, la opción del legislador europeo por la aprobación de un acto jurídico como la decisión marco, además de controvertida, como se comprobará en las páginas que siguen, tiene como efecto convertir la Decisión Marco 2002/584/JAI en una «fuente marginal de aproximación» de la regulación penal de los Estados miembros (Weyembergh, 2005: 149).

Pero, al mismo tiempo, la adopción por la Unión Europea de la regulación sobre la OEDE sin haber armonizado previamente el listado de delitos - entre otras particularidades_-, puede entenderse como una evidencia de que la Comisión no consideraba la «armonización total como una necesidad absoluta" para el funcionamiento del reconocimiento mutuo (Bantekas, 2007: 368), de ahí que haya podido ser considerada como una «alternativa» a la armonización (Asp, 2005: 31).

\section{LA PROBLEMÁTICA DE LAS DECISIONES MARCO EN EL ORDENAMIENTO JURÍDICO DE LA UNIÓN EUROPEA}

\section{EL CUESTIONAMIENTO DE LOS EFECTOS JURÍDICOS DE LAS DECISIONES MARCO COMO ACTOS JURÍDICOS DEL DERECHO DE LA UE}

Desde tales premisas, la discusión sobre la eficacia jurídica de las decisiones marco tuvo como telón de fondo la comparación de sus caracteres con las directivas reguladas en el entonces art. 249.3 TCE, con las que compartían ciertos rasgos - obligaban a los Estados miembros al cumplimiento del resultado, aunque estos disponían de capacidad de elección respecto de la forma y los medios-, pero también mantenían diferencias sustanciales que evidenciaban la falta de identidad entre el primero y el tercer pilar del TUE como ámbitos diferenciados de la actuación de estos actos jurídicos de la Unión.

Uno de los aspectos distintivos más relevantes entre las decisiones marco (tercer pilar) y las directivas (primer pilar) proviene del hecho de que el Tratado CE preveía la monitorización por la Comisión Europea de la transposición de las segundas, disponiendo de la legitimación, en su caso, para promover el recurso por incumplimiento ante el Tribunal de Justicia contra un Estado miembro (art. 226 TCE).

Por el contrario, el Tratado de Ámsterdam no contemplaba la misma monitorización por la Comisión Europea respecto de la traslación de las deci- 
siones marco al ordenamiento jurídico de los Estados miembros, careciendo la Comisión de legitimidad activa para promover el recurso por incumplimiento ante el Tribunal de Justicia en caso de una inadecuada adaptación de dichos actos jurídicos por un Estado miembro.

Esta circunstancia, en opinión de Borgers (2007: 1369-1370), venía a confirmar que la «soberanía de los Estados miembros tiene más peso» en el tercer pilar que en el primer pilar, y así se puso de manifiesto, por lo demás, cuando varios Tribunales Constitucionales de Estados miembros, como el polaco, el alemán y el chipriota, anularon la normativa nacional de implementación de la Decisión Marco 2002/584/JAI por contravenir la prohibición constitucional de que los nacionales de dichos Estados sean extraditados.

Específicamente, la Sentencia del Tribunal Constitucional polaco de 27 de abril de $2005^{10}$ reconoció la inconstitucionalidad de la normativa de implementación de la Decisión Marco 2002/584/JAI, aunque, en aplicación del párrafo 3 del art. 190 de la Constitución, difirió en dieciocho meses los efectos de la declaración de inconstitucionalidad ${ }^{11}$.

Por su parte, la Sentencia del Tribunal Constitucional Federal alemán de 18 de julio de $2005^{12}$ anuló con efecto inmediato la normativa nacional de transposición de la decisión marco sobre la OEDE, por considerar que vulneraba el contenido esencial del derecho fundamental proclamado en el art. 16, apartado 2, de la Ley Fundamental de Bonn, que prohibía que un alemán fuera entregado a un Estado extranjero ${ }^{13}$.

En el mismo sentido, el Tribunal Supremo de Chipre declaró inconstitucional en la Sentencia de 7 de noviembre de 2005 (Asunto 294/2005), la regulación nacional de trasposición de la OEDE por contravenir la prohibición constitucional de que los nacionales de ese Estado miembro fueran extraditados a cualquier otro país ${ }^{14}$.

10 OTK ZU (Jurisdiction of the Constitutional Tribunal. Official Collection) No 4/A/2005, item 42 - Dz.U. No 77, item 680, 4 May, 2005. Versión en inglés disponible en: https://bit.ly/2Ddtl48.

11 En relación con esta Sentencia del Tribunal Constitucional Polaco, véanse Łazowski (2005), Nußberger (2008), y Wyrozumska (2004-2005).

12 BVerfGE 113, 273 (2 BvR 2236/04). Versión en inglés disponible en: https://bit. ly/2OgQMQi.

13 Comentando este pronunciamiento del Tribunal Constitucional Federal alemán, véanse Hinarejos (2006: 583-595), Nohlen (2008: 153-161), y Tomuschat (2006: 209-226).

14 Resumen del pronunciamiento publicado por el Consejo de la Unión Europea. Nota. 14281/05, de 11 de noviembre de 2005 (versión en inglés). Comentando esta sentencia, véase Tsadiras (2007: 1515-1528). 
Unos límites constitucionales que los tribunales constitucionales antes citados anteponían a la Decisión Marco 2002/584/JAI, dado que el Tratado de Ámsterdam (art. K.6.2.b y art. 34.2.b del TUE) reconocía que estos actos jurídicos de la Unión «no tendrán efecto directo».

Esta afirmación fue objeto de interpretación por el Tribunal de Justicia en la Sentencia de 16 de junio de 2005, Pupino, Asunto C-105/03 $3^{15}$, estimando que, con independencia del grado de integración entre el primero y el tercer pilar alcanzado por el Tratado de Ámsterdam, resulta comprensible que los autores del Tratado de la Unión europea hayan considerado útil prever el recurso a instrumentos jurídicos que conllevan efectos análogos con el fin de «contribuir eficazmente a la consecución de los objetivos de la Unión» (párr. 36) ${ }^{16}$. Porque, en última instancia, afirma, la competencia prejudicial del Tribunal de Justicia se vería privada de su efecto útil si los particulares no tuvieran el derecho de invocar las decisiones marco con el fin de obtener una decisión conforme del derecho nacional ante los tribunales de los Estados miembros (párr. 38).

De este modo, el Tribunal de Justicia concluye que el principio de interpretación conforme se impone respecto de las decisiones marco adoptadas en el ámbito del tercer pilar del Tratado UE, y, en consecuencia, al aplicar el derecho nacional el juez de reenvío llamado a interpretarlo está obligado a hacerlo, en la medida de lo posible, «a la luz de la letra y del propósito de la Decisión Marco con el fin de conseguir el resultado" perseguido por ella (párr. 43) ${ }^{17}$.

Un análisis conjunto de los pronunciamientos anteriores se encuentra, entre otros, en Bapuly (2009: 16-22), Iglesias Sánchez (2010: 169-192) y Komárek (2007: 9-40).

15 La República italiana realizó una declaración ad hoc con arreglo al art. 35 UE, apartado 2, mediante la cual aceptó la competencia del Tribunal de Justicia para pronunciarse según las modalidades previstas en el art. 35 TUE, apartado 3, letra b) (DOCE L 114/56, de 1-5-1999).

16 A juicio de Peers (2007: 915-917), la referencia a la intención de los autores de los tratados implica reconocer la preeminencia de los Estados miembros como «dueños de los Tratados», pero, al mismo tiempo, plantea nuevas preguntas acerca de las bases sobre las que debe interpretarse el tercer pilar: «¿Por referencia al texto del Tratado y a la intención de sus autores?, ¿por referencia a la efectividad de la jurisdicción del Tribunal?», o "¿por referencia a la efectividad en el desarrollo de las acciones de la UE en el marco del desarrollo de una unión cada vez más estrecha?».

17 El argumento de la interpretación conforme fue asumido por el Tribunal Constitucional checo en su Sentencia de 3 de mayo de 2006 (Pl. ÚS 66/04) para equiparar los estándares de garantías en los procedimientos penales de los Estados miembros de la UE a los establecidos en el texto de la Constitución nacional checa en relación con la 
El recurso por el Tribunal de Justicia al argumento de la interpretación conforme resulta, a juicio de Borgers (2007), una afirmación «destacable» desde la perspectiva de la asimilación de la decisión marco a las directivas, de modo que, en su opinión, a través de la sentencia Pupino, el Tribunal de Justicia ha llevado a cabo una "comunitarización» del tercer pilar ${ }^{18}$, aun cuando ello no supone, afirma, que la sentencia Pupino admita el efecto directo de las decisiones marco de manera que la diferencia entre estas y las directivas "(todavía) no ha desaparecido» ${ }^{19}$.

\section{LAS DUDAS DE CARÁCTER FORMAL Y MATERIAL RELATIVAS A LA DECISIÓN MARCO SOBRE LA ORDEN EUROPEA DE DETENCIÓN Y ENTREGA}

El recurso del Tribunal de Justicia al criterio de la interpretación conforme en relación con las decisiones marco permite preguntarse «cuál es la base legal en el derecho $U E »$ de dicha obligación, y, más concretamente, si el art. 34.2.b TUE (art. K.6.2.b del Tratado de Ámsterdam) proporciona un fundamento legal «suficiente» para la misma (Borgers, 2007: 1367-1368, nota 22).

Una cuestión de carácter formal específicamente referida a la Decisión Marco 2002/584/JAI, sobre la que se pronunció el Tribunal de Justicia de la UE en la Sentencia de 3 de mayo de 2007, Advocaten voor de Wereld VZW $c$. Leden van de Ministerraad, Asunto C-303/05, resolviendo una cuestión prejudicial de validez planteada por el Arbitragehof o Cour d'arbitrage de Bélgica (órgano jurisdiccional encargado del control de constitucionalidad de las leyes).

En este primer pronunciamiento acerca de la validez en el ordenamiento jurídico europeo de la Decisión Marco 2002/584/JAI, el Tribunal de Jus-

prohibición de extradición de nacionales de ese Estado, y, en consecuencia, reconocer la conformidad constitucional de la normativa de implementación de la Decisión Marco 2002/584/JAI (Sarmiento, 2008: 174). No obstante, aparecía como obiter dicta en un pronunciamiento previo de 8 de marzo de 2006, en el que se cuestionaba la conformidad constitucional de un decreto del Gobierno que trasponía la normativa europea sobre las cuotas del azúcar (Zemánek, 2007: 424-425).

18 A la luz también del contenido del art. 34(2) TUE, Lenaerts y Corthaut (2006: 300301) consideran posible entender que el hecho de que las decisiones marco carezcan de efecto directo no les impide «formar parte de las reglas a la luz de las cuales puede ser revisada la validez de una medida nacional».

19 En todo caso, la definición exacta del efecto directo es objeto de un constante desacuerdo a cuyo decurso ha contribuido el «uso impreciso» del mismo por el Tribunal de Justicia, que no ha favorecido su clarificación (Hinarejos, 2008: 623-624). 
ticia aclaró, de un lado, que el principio de reconocimiento mutuo en que se basa la OEDE requiere, según afirma, «la aproximación de las disposiciones legales y reglamentarias de los Estados miembros relativas a la cooperación judicial en materia penal», y, más concretamente, de las «normas sobre los requisitos, procedimientos y efectos de la entrega entre autoridades nacionales» (párr. 29).

Sin embargo, el art. 31 del Tratado UE, afirma, no concreta los instrumentos jurídicos que deben ser utilizados para facilitar y acelerar la cooperación judicial respecto de la ejecución de resoluciones y la extradición entre Estados miembros, por lo que la OEDE se podía haber regulado mediante un Convenio, aunque también resulta admisible, a su juicio, que «el Consejo, en ejercicio de su facultad de apreciación», puede priorizar el uso de la decisión marco cuando se cumplen los requisitos para su adopción (párr. 41), dando, en definitiva, «luz verde a este instrumento emblemático de la cooperación judicial europea en materia penal» (Geyer, 2008: 151).

Asimismo, la sentencia Advocaten voor de Wereld VZW c. Leden van de Ministerraad aborda la relevante cuestión sustantiva relativa a la posible vulneración del principio de legalidad penal por el art. 2.2 de la decisión marco sobre la OEDE. A este respecto, el Tribunal de Justicia considera que la decisión marco no tiene por objeto armonizar las infracciones penales en cuanto a sus «elementos constitutivos» o las "penas correspondientes».

En consecuencia, afirma que, aun en el supuesto de que los Estados miembros apliquen literalmente las categorías de infracciones penales enumeradas en su art. 2, apartado 2, «la propia definición de estas infracciones y las penas aplicables son las establecidas en el Derecho del "Estado miembro emisor”" (párr. 52), que, en todo caso, deberá respetar los derechos fundamentales y los principios jurídicos fundamentales consagrados en el art. $6 \mathrm{UE} \mathrm{y,} \mathrm{en}$ consecuencia, «el principio de legalidad de los delitos y las penas» (párr. 53).

\section{LA ORDEN EUROPEA DE DETENCIÓN Y ENTREGA COMO SISTEMA DE LIBRE CIRCULACIÓN DE RESOLUCIONES JUDICIALES EN MATERIA PENAL}

\section{LA OBLIGACIÓN DE EJECUTAR LA ORDEN EUROPEA DE DETENCIÓN Y ENTREGA Y SUS EXCEPCIONES «TASADAS»}

Desde tales premisas, el Considerando 5 de la decisión marco sobre la OEDE afirma que responde al objetivo atribuido a la Unión de llegar a ser un espacio de libertad, seguridad y justicia, dando lugar a la sustitución de 
la extradición entre los Estados miembros por un «sistema de entrega entre autoridades judiciales $»^{20}$.

La creación de un nuevo sistema simplificado de entrega de personas condenadas o sospechosas, con fines de ejecución de las sentencias o de diligencias en materia penal, suprime la complejidad y los riesgos de los procedimientos tradicionales de extradición basados en las relaciones de cooperación entre Estados, reemplazándolos por un sistema de libre circulación de resoluciones judiciales en materia penal, tanto "previas a la sentencia como definitivas», en el espacio de libertad, seguridad y justicia.

Así, el apartado 1 del art. 1 de la Decisión Marco 2002/584/JAI define la OEDE como una «resolución judicial» dictada por un órgano jurisdiccional de un Estado miembro con vistas a la detención y entrega por otro Estado miembro de una persona buscada en el Estado emisor para el ejercicio de acciones penales o para la ejecución de una pena o una medida de seguridad privativas de libertad.

Una detención y entrega que, como prevé el apartado 2 del art. 1, se fundamenta en el principio de reconocimiento mutuo, como, por lo demás, enuncia su Considerando 6, al afirmar que «la orden de detención europea prevista en la presente Decisión Marco es la primera concreción en el ámbito del Derecho penal del principio del reconocimiento mutuo que el Consejo Europeo ha calificado como "piedra angular" de la cooperación judicial».

De este modo, frente al principio de la extradición multilateral en el que un Estado requiere a otro asistencia en algún aspecto de la actuación de su sistema de justicia penal, y el Estado requerido adopta una decisión de cooperar atendiendo a «su propio sistema jurídico», aun cuando la discrecionalidad del Estado requerido pueda estar condicionada por diferentes normas de derecho internacional, en el sistema del reconocimiento mutuo, «la resolución del primer Estado (ahora "Estado de emisión") surte efecto como tal en el sistema jurídico del segundo Estado (ahora "Estado de ejecución")».

No obstante, dependiendo del instrumento en cuestión, el Estado de ejecución mantiene alguna capacidad de rechazo a la ejecución o a la traslación de la resolución del Estado de emisión en su propio ordenamiento jurídico (Peers, 2004: 10).

20 Entre los aspectos del régimen de la extradición que la Decisión Marco 2002/584/JAI sustituye y reemplaza entre los Estados miembros, se encuentra el aspecto, según ha reconocido el Tribunal de Justicia, de que la decisión marco «ya no tiene en cuenta la magnitud de las penas aplicables en los Estados miembros de ejecución", en coherencia con el objetivo primordial que persigue, enunciado en su Considerando 5 (Auto TJUE, de 25 de septiembre de 2015, Openbaar Ministerie, Asunto C-463/15 PPU). 
Más concretamente, en el nuevo esquema de la decisión marco sobre la OEDE, la cooperación y comunicación, caso por caso, entre autoridades gubernamentales, se sustituye por la comunicación directa entre órganos judiciales $^{21}$, convirtiéndolos en «responsables exclusivos» de la entrega de los individuos a otros Estados miembros. Una responsabilidad exclusiva de los órganos judiciales que, en el sistema tradicional de extradición, «[solían] compartir con los ejecutivos» (Van Sliedregt, 2007: 248-249), con la consiguiente «discrecionalidad política» sobre la entrega, que desaparece en el sistema de libre circulación de resoluciones judiciales establecido por la OEDE.

Al mismo tiempo —en aras de alcanzar una mayor sumariedad en el procedimiento-, ciertos «tecnicismos» dirigidos a proteger los derechos del sospechoso y del condenado vienen a ser sustituidos por la confianza de los Estados miembros sobre la «imparcialidad» de los sistemas de Justicia penal de otros Estados miembros, respaldada por la «común adhesión» a la Convención Europea de Derechos Humanos y la «común aceptación» del derecho de petición individual (Denza, 2002: 257).

En definitiva, el reconocimiento mutuo en el que se sustenta la OEDE implica, según los términos imperativos utilizados en el art. 1.2 de la Decisión Marco 2002/584/JAI, que, en principio, los Estados miembros están obligados a ejecutar toda orden de detención europea, y así lo ha recordado, haciendo mención a su reiterada jurisprudencia, el Tribunal de Justicia de la UE en la Sentencia de 16 de julio de 2015 (Gran Sala), Lanigan, Asunto C-237/15 PPU (párr. 36), aunque, al mismo tiempo, ha admitido que esta obligación no tiene carácter absoluto.

Efectivamente, como también ha afirmado el Tribunal de Justicia en la Sentencia de 5 de abril de 2016 (Gran Sala), Aranyosi-Căldăraru, Asuntos acumulados C-404/15 y C-659/15 PPU, según su propia doctrina, las excepciones al principio general de obligatoriedad de la ejecución de la orden europea de detención y entrega deben interpretarse como supuestos «tasados».

21 En la Sentencia de 10 de noviembre de 2016, Poltorak, Asunto C-452/16 PPU, el Tribunal de Justicia precisa que el concepto de autoridad judicial recogido en el art. 6.1 de la decisión marco sobre la OEDE constituye un "concepto autónomo» del Derecho de la Unión, que no incluye, por ejemplo, a un servicio de policía como la Dirección General de la Policía Nacional sueca, que no puede considerarse como autoridad judicial emisora de una orden europea de detención (párr. 59).

En el mismo sentido, la Sentencia de 10 de noviembre de 2016, Kovalkovas, Asunto C-477/16 PPU, también rechaza que el Ministerio de Justicia de la República de Lituania pueda ser designado como autoridad judicial emisora de una orden europea de detención (párr. 55). 
En consecuencia, afirma, la autoridad jurisdiccional de ejecución «sólo podrá negarse» a ejecutarla en los supuestos, enumerados exhaustivamente de no ejecución obligatoria, establecidos en el art. 3 de la decisión marco, y en los de no ejecución facultativa, enunciados en los arts. 4 y 4 bis de la decisión marco. Además, la ejecución de la orden de detención europea únicamente podrá supeditarse a las condiciones definidas expresamente en el art. 5 de dicha decisión marco (párr. 80).

Así, la opción del legislador europeo de limitar los supuestos en los que la autoridad jurisdiccional de ejecución puede negarse a ejecutar una OEDE tiene como finalidad última, precisamente, garantizar que el principio continúa siendo que las órdenes europeas de detención y entrega son ejecutadas (Klimek, 2015).

Pero en todo caso, el principio de reconocimiento mutuo no ha supuesto una reducción sustancial de los motivos de no ejecución enunciados en la decisión marco sobre la OEDE, identificables sustancialmente con supuestos de no ejecución mencionados habitualmente en los tratados y en las legislaciones nacionales de extradición, por lo que, desde esta perspectiva, afirma, hay espacio para la «desconfianza» (Van Sliedregt, 2007: 248-249).

\section{LA RESOLUCIÓN DE 15 DE DICIEMBRE DE 2015 DEL TRIBUNAL CONSTITUCIONAL FEDERAL ALEMÁN COMO QUIEBRA DEL SISTEMA}

Precisamente una muestra de ello la ha proporcionado el Tribunal Constitucional Federal alemán en su Resolución de 15 de diciembre de $2015^{22}$, al invocar la aplicación de la Ley Fundamental para denegar la ejecución de una OEDE previamente aceptada por el Tribunal Superior Regional de Düsseldorf (Oberlandesgericht), basándose en el principio de reserva de la identidad

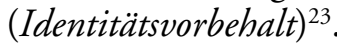

Al declarar que todas la autoridades jurisdiccionales alemanas deben aplicar el principio de reserva de la identidad constitucional como criterio de ejecución de la orden europea de detención y entrega, la Resolución de 15 de diciembre de 2015 se convierte, a juicio de Hong (2016: 550), en una resolu-

22 BVerfG, Order of 15 December 2015, 2 BvR 2735/14. Versión en inglés disponible en: https://bit.ly/2seSqth.

23 En realidad, como afirman T. Reinbacher y M. Wendel (2016: 704), el término «identidad» no aparece explícitamente mencionado en la Ley Fundamental, pero es utilizado por el Tribunal Constitucional Federal «como sinónimo del núcleo constitucional inalienable», que, en materia de derechos fundamentales, se encuentra protegido por la denominada «cláusula de intangibilidad en el art. 79(3) GG» frente a las reformas constitucionales. 
ción «histórica», a través de la cual el Tribunal Constitucional Federal alemán lanza el siguiente «mensaje clave» respecto de aplicación de la Decisión Marco 2002/584/JAI: «[...] en tanto la Constitución alemana permanezca en vigor, el Tribunal Constitucional Federal alemán aplicará el derecho constitucional a la dignidad humana, a pesar del derecho de la Unión Europea».

Desde luego, la citada resolución del Tribunal Constitucional Federal alemán —conocida comúnmente por la doctrina como EAW II (en sus siglas en inglés, por referencia a la Sentencia de 18 de julio de 2005 antes mencionada), pero también como Solange horizontal (Canor, 2013), Solange III (Reinbacher y Wendel, 2016; Hong, 2016) ${ }^{24}$ o Forever I (Meyer, 2016) ${ }^{25}$-, otorga el amparo solicitado contra la resolución del Tribunal Superior Regional de Düsseldorf (Oberlandesgericht) de 7 de noviembre de 2014.

En consecuencia, rechaza la conformidad constitucional de la decisión de la autoridad jurisdiccional regional alemana de ejecutar una OEDE presentada por un tribunal de Florencia (Italia) respecto de un ciudadano americano condenado en rebeldía a una pena privativa de libertad, por entender que el principio de culpabilidad penal se basa en la garantía de la dignidad humana reconocida en el art. 1.1 de la Ley Fundamental ${ }^{26}$.

La garantía de la dignidad humana ${ }^{27}$, en palabras del Tribunal Constitucional Federal alemán, no solo forma parte de la identidad constitucional que

24 Según estiman Reinbacher y Wendel (2016: 704), la utilización del término Solange III para referirse a este pronunciamiento no es tanto en el sentido de que suponga «un nuevo enfoque paradigmático», sino como una concreción del concepto ya conocido por el Tribunal de reserva de la identidad (Identitätsvorbehalt). Una interpretación que viene avalada por la circunstancia de que dicha resolución no menciona expresamente el término «mientras que» (solange), aunque, a juicio de M. Hong (2016), ello no es óbice para que pueda ser referenciada válidamente como Solange III. .

En opinión de Meyer (2016), denominar a esta decisión del Tribunal Constitucional Federal Solange III podría describir de forma errónea su repercusión, proponiendo, a tales efectos, la de Forever I en tanto que, en ella, el Tribunal Constitucional Federal alemán insiste en que «tiene» $\mathrm{y}$ «siempre tendrá» la autoridad ilimitada y suprema para conocer sobre todos los principios implicados que estén incluidos en la denominada cláusula de intangibilidad (Ewigkeitsgarantie).

26 Precisamente con anterioridad a la entrada en vigor de la Decisión Marco 2002/584/ JAI, Fonseca (2003: 92) se preguntaba, premonitoriamente, si, con carácter general, cabía «temer» que, por referencia a los derechos fundamentales, un Estado miembro pudiera imponer a los otros algunos elementos de su sistema judicial.

27 En términos generales, el Tribunal Constitucional Federal ha reconocido que la dignidad humana constituye el fundamento de «todos los derechos constitucionales» y que todos ellos concretan el principio de dignidad. Un concepto de «núcleo duro» 
es inalienable según el art. 79.3 de la Ley Fundamental, sino que también está «protegida frente a interferencias» de autoridades públicas ejercidas a nivel supranacional (párr. 53), y ello, afirma, «a pesar de que el principio de reconocimiento mutuo regula las extradiciones en Europa» (párr. 63).

Una interpretación en la que, según estiman Reinbacher y Wendel (2016), el Tribunal Constitucional Federal alemán evita el conflicto, asumiendo el paralelismo sustancial entre los derechos fundamentales a nivel nacional y europeo, y concluyendo que las exigencias del Derecho de la UE no son menores que los mínimos exigidos por el art. 1(1) de la Ley Fundamental (párr. 107).

En este contexto, la asunción por el Tribunal Constitucional Federal alemán de la función de intérprete del ordenamiento de la UE resulta especialmente destacable en relación con la distribución de las competencias judiciales en el pluralismo europeo de los derechos fundamentales. Aun cuando se ha tratado de justificar como un medio para evitar la suerte del Tribunal Constitucional español en el asunto Melloni (Reinbacher y Wendel, 2016: 711-712), lo cierto es que la consecuencia última del pronunciamiento del Tribunal Constitucional Federal alemán plantea la pregunta (Nowag, 2016: 1449) acerca de cuáles son los límites de este «superderecho humano».

De este modo, situando la cuestión en el marco del sistema de garantías de los derechos fundamentales en el ordenamiento europeo, la Resolución del Tribunal Constitucional Federal alemán de 15 de diciembre de 2015 también «ilustra vívidamente» los efectos perjudiciales que pueden darse en las actuales condiciones de inexistencia de un recurso directo respecto a los derechos fundamentales ante el Tribunal de Justicia de la UE.

En este sentido, a través de la imposición de límites constitucionales al principio de reconocimiento mutuo, a juicio de Meyer (2016: 282), el Tribunal Constitucional Federal alemán ha dado lugar a una línea de fractura

o «esencia» de los derechos fundamentales obtenido a partir del derecho a la dignidad humana, inalterable incluso a través de la reforma constitucional, que ha venido siendo ampliamente desarrollado por la jurisprudencia del Tribunal Constitucional federal.

Esta interpretación, que en un primer momento se llevó a cabo respecto de los derechos de propiedad y de igualdad (art. 14 y art. 3 GG, respectivamente) en el marco de sus pronunciamientos sobre las ocupaciones comunistas de tierras en Alemania Oriental, fue extendida en su sentencia de 2004 sobre control acústico en los hogares, a través del concepto de contenido de dignidad (Menschenwürdegehalt) en referencia a estos elementos inalterables de los derechos fundamentales, afirmando que la dignidad protege un núcleo duro de privacidad frente a cualquier injerencia (Hong, 2016: 558-559). 
de graves consecuencias para el desarrollo de los estándares comunes de los derechos fundamentales europeos.

\section{LA RUPTURA EXCEPCIONAL DEL PRINCIPIO DE CONFIANZA RECÍPROCA Y LA ARTICULACIÓN DEL TEST ARANYOSI}

En efecto, en la Sentencia de 5 de abril de 2016 (Gran Sala), Aranyosi-Căldăraru, Asuntos acumulados C-404/15 y C-659/15 PPU, el Tribunal de Justicia de la UE, sin hacer mención alguna a la anterior resolución del Tribunal Constitucional Federal alemán, trata de limitar su impacto y «mantener la caja de Pandora al menos semi-cerrada» (Meyer, 2016: 285).

Así, por primera vez permite a las autoridades jurisdiccionales de los Estados miembros abstenerse de aplicar, con carácter excepcional, la Decisión Marco 2002/584/JAI, invocando el art. 4 de la Carta de Derechos Fundamentales de la Unión Europea (prohibición de la tortura y de las penas o los tratos inhumanos o degradantes) ${ }^{28}$, en relación con la previsión contenida en el art. 1.3 de la decisión marco, según la cual dicho acto jurídico no podrá suponer una modificación de la obligación de los Estados miembros de respetar los derechos fundamentales y los principios jurídicos fundamentales proclamados en el art. 6 del Tratado de la Unión Europea.

Una sentencia dictada en el contexto de la resolución de las cuestiones prejudiciales de interpretación sobre el art. 1, apartados 3 y 5, y el art. 6, apartado 1, de la decisión marco sobre la OEDE, planteadas por el Hanseatisches Oberlandesgericht de Bremen (Tribunal Superior Regional Civil y Penal de Bremen, Alemania) con motivo de la ejecución de dos órdenes europeas de detención y entrega emitidas, respectivamente, por el juez de instrucción del Tribunal Comarcal de Miskolc (Hungría), contra el Sr. Aranyosi, y por el Judecătoria Făgăraş (Tribunal de Primera Instancia de Fagaras, Rumanía), contra el Sr. Căldăraru.

Hasta ese momento ningún asunto relativo a la OEDE resuelto por el Tribunal de Justicia había revelado fisuras insuperables en la construcción de

28 Las Explicaciones sobre la Carta de los Derechos Fundamentales (2007/C 303/02) precisan que el art. 4 de la Carta tiene el mismo tenor que el art. 3 del Convenio Europeo de Derechos Humanos (CEDH), y en virtud del apartado 3 del art. 52 de la Carta, el mismo sentido y alcance que este último.

Precisamente, como subraya Bustos (2016), a diferencia del asunto Melloni, en la sentencia Aranyosi-Căldăraru no se plantea que la OEDE genere una vulneración de los derechos reconocidos en un Estado miembro, sino de los derechos reconocidos en el CEDH, y, en consecuencia, en la Carta de los Derechos Fundamentales de la UE. 
los supuestos reconocidos de no ejecución que hicieran necesario recurrir a los derechos fundamentales para proporcionar suficiente protección (Meyer, 2016). De hecho, el análisis de la jurisprudencia del Tribunal de Justicia anterior a la sentencia Aranyosi-Căldăraru revela, a juicio de Mitsilegas (2015), que este siempre había dado preferencia a la aplicación del principio de reconocimiento mutuo fundado en la confianza recíproca, en detrimento de la protección de los derechos fundamentales del individuo.

Sin embargo, expresada en palabras del abogado general Sr. Yves Bot el 3 de marzo de 2016, la cuestión subyacente ahora es «si es posible limitar la fuerza del principio de reconocimiento mutuo cuando se quiebra la confianza que se deben los Estados miembros debido a una posible violación de los derechos fundamentales que se entiende éstos han de respetar» (párr. 3), o, según afirma Lenaerts (2017: 821), si el principio de confianza recíproca debe entenderse como una "confianza ciega».

El punto de partida del razonamiento del Tribunal de Justicia en la sentencia Aranyosi-Căldăraru se sitúa en su Dictamen 2/13, de 18 de diciembre de 2014 (Pleno), Adhesión de la Unión al CEDH, y en la constatación de que el Derecho de la Unión se asienta en la premisa fundamental de que todo Estado miembro comparte con todos los demás, y reconoce que estos comparten con él, unos «valores comunes» en los que se fundamenta la Unión (art. 2 TUE).

De este postulado, afirma, deriva la existencia de una confianza recíproca entre los Estados miembros en el reconocimiento de esos valores y, en consecuencia, en el respeto del Derecho de la Unión donde son aplicados (párr. 168), salvo que concurran "circunstancias excepcionales» (párr. 191). Un principio de confianza recíproca en el respeto de los derechos fundamentales por los Estados miembros que, por lo demás, se enuncia expresamente en los Considerandos 10 y 12 de la decisión marco sobre la $\mathrm{OEDE}^{29}$.

29 El Considerando 10 afirma: «El mecanismo de la orden de detención europea descansa en un grado de confianza elevado entre los Estados miembros. Su aplicación sólo podrá suspenderse en caso de violación grave y persistente, por parte de uno de los Estados miembros, de los principios contemplados en el apartado 1 del artículo 6 del Tratado de la Unión Europea, constatada por el Consejo en aplicación del apartado 1 del artículo 7 de dicho Tratado, y con las consecuencias previstas en el apartado 2 del mismo artículo».

Por su parte, el Considerando 12 establece: «La presente Decisión marco respeta los derechos fundamentales y observa los principios reconocidos en el artículo 6 del Tratado de la Unión Europea y reflejados en la Carta de los derechos fundamentales de la Unión Europea, en particular en su capítulo VI. Nada de lo dispuesto en la presente Decisión marco podrá interpretarse en el sentido de que impide la entrega de una persona contra la que se ha dictado una orden de detención europea cuando existan 
Desde tales premisas, en la sentencia Aranyosi-Căldăraru el Tribunal de Justicia estima que la cooperación judicial en materia penal en la Unión se conforma a partir de la superposición de distintos estratos, de manera que el principio de reconocimiento mutuo en el que se sustenta el sistema de la OEDE descansa, a su vez, en la confianza recíproca entre los Estados miembros en que sus respectivos ordenamientos jurídicos nacionales proporcionan una "protección equivalente y efectiva» de los derechos fundamentales reconocidos en el ámbito de la Unión, en particular en la Carta (párr. 77).

Sin embargo, al articular el test Aranyosi el Tribunal de Justicia se aparta del criterio establecido en el Considerando 10 de la decisión marco sobre la OEDE, que, a través de la remisión al procedimiento del art. 7 TUE, mantiene en el ámbito de las instituciones europeas la valoración acerca de la existencia de un riesgo real de vulneración de los derechos fundamentales en el Estado miembro emisor de una OEDE.

En efecto, tanto la decisión acerca de la concurrencia de una «circunstancia excepcional» que pueda implicar la ruptura del principio de reconocimiento mutuo como la propia valoración genérica y específica respecto del grado de respeto de los derechos fundamentales por el Estado miembro emisor de la OEDE mediante la aplicación del test Aranyosi recaen en el ámbito de la discrecionalidad de la autoridad jurisdiccional de ejecución de la OEDE.

Articulado a través de dos etapas o fases concurrentes, la primera de ellas —denominada «prueba del riesgo genérico» (Muñoz de Morales, 2017)— requiere que la autoridad jurisdiccional de ejecución disponga de información «objetiva», «fiable», «específica»y «actualizada» que acredite, según el caso de autos, que las condiciones de las prisiones en el Estado miembro emisor son incompatibles con el art. 4 de la Carta, en el sentido de que las deficiencias respecto de los derechos fundamentales resulten sistémicas o generalizadas en el mismo, afectando a ciertos grupos de personas o a ciertos centros de reclusión.

Los elementos para llevar a cabo esta comprobación, según el Tribunal de Justicia, pueden provenir de resoluciones judiciales internacionales, como las sentencias del Tribunal Europeo de Derechos Humanos, resoluciones ju-

razones objetivas para suponer que dicha orden de detención europea ha sido dictada con fines de persecución o sanción a una persona por razón de sexo, raza, religión, origen étnico, nacionalidad, lengua, opiniones políticas u orientación sexual, o que la situación de dicha persona pueda quedar perjudicada por cualquiera de estas razones. La presente Decisión marco no impedirá a ningún Estado miembro aplicar sus normas constitucionales relativas al respeto del derecho a un proceso equitativo, la libertad de asociación, libertad de prensa y libertad de expresión en los demás medios». 
diciales del Estado miembro emisor o decisiones, informes u otros documentos elaborados por los órganos del Consejo de Europa o del sistema de las Naciones Unidas (párr. 89). Pero la expresión «u otros documentos» parece admitir, a juicio de Marguery (2016: 953), un concepto demasiado amplio de las deficiencias que pueden afectar a los derechos fundamentales en un Estado miembro.

En todo caso, el resultado positivo a la primera fase del test Aranyosi no basta por sí mismo, a juicio del Tribunal de Justicia, para denegar la ejecución de una orden de detención europea (párr. 91), debiendo siempre activar su segunda fase, donde la autoridad jurisdiccional de ejecución deberá comprobar, "concreta y precisamente», si existen razones serias y fundadas para creer que la persona de que se trate correrá ese riesgo atendiendo a las condiciones de reclusión previstas para ella en caso de ser entregada (párr. 92).

A tales efectos, la autoridad jurisdiccional de ejecución podrá requerir información adicional al Estado miembro emisor, según las previsiones del art. 15.2 de la decisión marco sobre la $\mathrm{OEDE}^{30}$, decidiendo acerca de la entrega de la persona reclamada en los plazos prescritos en el art. 17 de la misma ${ }^{31}$,

30 En opinión de Bárd y Van Ballegooij (2018: 359), el intercambio de información entre las autoridades jurisdiccionales de ejecución y de emisión acerca de las condiciones específicas de reclusión previstas para la persona respecto de la que se ha emitido la OEDE supone el establecimiento de un «diálogo» entre órganos jurisdiccionales.

No obstante, la mera solicitud y remisión de estos datos entre órganos jurisdiccionales no puede entenderse propiamente como un "diálogo» entre tribunales en el sentido en que este concepto se ha venido utilizando por la doctrina en los años recientes, dado que, en puridad, no supone el «intercambio» de orientaciones jurisprudenciales, ni implica ningún tipo de "circulación» de pronunciamientos emitidos entre ambos tribunales (De Vergottini, 2010: 32-33).

31 El criterio del Tribunal de Justicia respecto de la interpretación conjunta de los arts. 15 y 17 de la decisión marco (según dictaminó en la Sentencia de 16 de julio de 2015, Lanigan, Asunto C-237/15 PPU) consiste en entender que el vencimiento de dichos plazos permite a la autoridad jurisdiccional de ejecución aplazar el cumplimiento de la orden europea de detención pero no supone su decaimiento (párr. 37).

Así, remitiéndose a la voluntad del «legislador de la Unión», su criterio consiste en interpretar que, en una situación en que no se hayan respetado esos plazos, «se aplazará la ejecución de la orden de detención europea, pero no se abandonará» (párr. 38). Esta interpretación, en virtud de la cual la decisión sobre la ejecución de una orden de detención europea puede adoptarse incluso después de expirados los plazos establecidos en el art. 17 de la decisión marco, evita, a juicio del Tribunal de Justicia, «que el efecto de las órdenes de detención europeas se debilite y que la dilación en la ejecución de esas órdenes acarree procedimientos más complejos» (párr. 41). 
y, en el supuesto de confirmar la concurrencia de un «riesgo real» de violación del derecho reconocido en el art. 4 de la Carta, podrá decidir si el procedimiento de entrega debe darse por concluido.

La perspectiva, según sostiene Lenaerts (2017: 821), es que el Tribunal de Justicia ha dejado claro en la sentencia Aranyosi-Căldăraru que la confianza recíproca no puede confundirse con "confianza ciega», sino que, por el contrario, debe ser "ganada» por el Estado miembro emisor a través del cumplimiento efectivo de los estándares de los derechos fundamentales de la $\mathrm{UE}^{32}$, y esta garantía, en el marco de la OEDE, debe ser apreciada atendiendo al carácter absoluto y, en consecuencia, no sujeto a limitaciones, de la prohibición de tratos inhumanos o degradantes reconocida en el art. 4 de la Carta (art. 3 $\mathrm{CEDH}$ ) (ibid.: 835).

No obstante, la remisión por el Tribunal de Justicia al test Aranyosi en la Sentencia de 25 de julio de 2018 (Gran Sala), LM. Asunto C-216/18 PPU ${ }^{33}$, donde se cuestiona por un órgano jurisdiccional irlandés la confianza recíproca en un supuesto de vulneración por el Estado emisor (en el caso de autos,

Sin embargo, la posibilidad de aplazar la ejecución de la orden de detención y entrega una vez sobrepasados los plazos previstos en el art. 17 de la Decisión Marco 2002/584/ JAI puede conllevar una ampliación del período de privación de libertad de la persona reclamada. Una circunstancia que no es rechazada por el Tribunal de Justicia al entender que el art.12 de la decisión marco en relación con el art. 17, y, a la luz de la Carta de Derechos Fundamentales de la Unión Europea, admite esa consecuencia «siempre que esa duración no sea excesiva en relación con las características del procedimiento", extremo que corresponderá valorar al órgano jurisdiccional remitente (párr. 63).

En todo caso, la construcción de un procedimiento de actuación como el test Aranyosi, que deberá atender a la casuística del supuesto, y, en consecuencia, será aplicado caso por caso, no puede entenderse, a juicio de Meyer (2016: 287), como una transformación del art. 1.3 de la decisión marco en una «excepción general de derechos fundamentales» en la aplicación de la OEDE por parte del Tribunal de Justicia.

El 1 de febrero de 2012, los órganos jurisdiccionales polacos (Sąd Okręgowy w Poznaniu [Tribunal Regional de Poznan], Sąd Okręgowy w Warszawie [Tribunal Regional de Varsovia] y Sąd Okręgowy w Włocławku [Tribunal Regional de Włocławek]) emitieron tres órdenes europeas de detención y entrega contra LM a efectos de su enjuiciamiento penal por tráfico ilícito de estupefacientes y sustancias psicotrópicas. El 5 de mayo de 2017, LM fue detenido en Irlanda en virtud de las mismas, compareciendo ante el Tribunal Superior (High Court, Irlanda), ante el que manifestó su falta de consentimiento a su entrega a las autoridades polacas por estimar que las recientes reformas legislativas del sistema judicial en la República de Polonia lo privan de su derecho a un proceso equitativo, refiriéndose, en particular, a la propuesta motivada de la Comisión Europea, de 20 de diciembre de 2017, presentada de conformidad con el art. 7.1 TUE, relativa al Estado de derecho en Polonia. 
Polonia) de un derecho de carácter no absoluto como es el derecho a un proceso equitativo contemplado en el art. 47 de la Carta $(\text { art. } 6 \mathrm{CEDH})^{34}$, ofrece precisiones relevantes acerca de las circunstancias que posibilitan la aplicación del test Aranyosi.

Dando por constatada la existencia de una violación general y sistémica de los derechos fundamentales en el Estado miembro emisor como consecuencia de la activación del procedimiento previsto en el art. 7.1 TUE respecto de Polonia, la autoridad jurisdiccional irlandesa pregunta al Tribunal de Justicia si se mantiene la obligación de recabar de las autoridades emisoras de la OEDE la información complementaria - que constituiría la segunda fase del test Aranyosi-, o bien de esa primera verificación cabe excluir que estas puedan proporcionar garantías específicas de que esa persona vaya a disfrutar de un proceso equitativo ${ }^{35}$.

En respuesta al reenvío prejudicial - y en consonancia con el Considerando 10 de la decisión marco sobre la OEDE_-, el Tribunal de Justicia comienza por descartar que el Tribunal Superior irlandés pueda establecer por sí mismo la correlación entre la activación del procedimiento previsto en el art. 7.1 TUE respecto de Polonia, y la suspensión uniltateral de la aplicación de la OEDE.

Concretamente, considera que la autoridad jurisdiccional irlandesa no está facultada para denegar automáticamente — sin tener que realizar ninguna comprobación - cualquier OEDE emitida por Polonia, sin que, con carácter previo, «exista una decisión del Consejo Europeo» por la que se constate una violación «grave» y «persistente» en el Estado miembro emisor de los principios contemplados en el art. 2 TUE, «seguida de la suspensión por el Consejo de la aplicación» de la Decisión Marco 2002/584/JAI (párr. 72).

34 El Tribunal de Justicia considera que la independencia de los órganos jurisdiccionales forma parte del «contenido esencial» del derecho a un proceso equitativo, y así, refiriéndose a su Sentencia de 27 de febrero de 2018, Associação Sindical dos Juízes Portugueses, Asunto C-64/16, y la jurisprudencia en ella citada, sistematiza y detalla los contenidos de la independencia judicial entonces enunciados (párrs. 42-45).

De hecho, a juicio de Sarmiento (2018: 386), la sentencia Associação Sindical dos Juizes Portugueses (párrs. 30-37) anticipa parcialmente el razonamiento del Tribunal de Justicia en el asunto $L M$, al reconocer que un debilitamiento de la independencia de los órganos judiciales nacionales puede implicar una vulneración del art. 19 TUE y, en última instancia, del Estado de derecho como valor común contemplado en el art. 2 TUE.

35 High Court of Ireland decision of 12 March 2018, Minister of Justice v. Celmer (2018 IEHC 119). 
En consecuencia, el Tribunal de Justicia remite a la autoridad jurisdiccional irlandesa al art. 1, apartado 3, de la decisión marco sobre la OEDE, y a las "circunstancias excepcionales» que justifican la aplicación de las dos etapas del test Aranyosi, convirtiendo a dicho precepto de la decisión marco en excepción general de derechos fundamentales en la aplicación de la OEDE, y reconociendo la aplicabilidad del test Aranyosi a la violación potencial de cualquier derecho fundamental.

\section{CONCLUSIONES}

Desde sus orígenes, la decisión marco sobre la OEDE ha sido percibida como una «nueva criatura del Derecho UE al mismo tiempo fascinante y controvertida» (Mathisen, 2010: 2), y, ciertamente, su morfología jurídica dista mucho de proporcionar la mínima seguridad jurídica que se deriva de la aplicación uniforme del derecho de la Unión en otros ámbitos competenciales.

La singular eficacia jurídica de las decisiones marco en el ordenamiento de la Unión explica, en gran medida, su vigencia hasta nuestros días, y trae causa del carácter sensible de su objeto respecto de la soberanía de los Estados miembros.

Como se ha comprobado en las páginas anteriores las peculiaridades de estos actos jurídicos han resultado determinantes no solo, inicialmente, en la opción del legislador europeo por el instrumento jurídico de la decisión marco en el ámbito del tercer pilar del Derecho originario, sino también en la propia pervivencia de este instrumento jurídico en el contexto del Tratado de Lisboa. Ello explica que la decisión marco sobre la OEDE no haya sido sustituida a día de hoy por una directiva, en la línea de otros aspectos de la cooperación en materia penal, como la Directiva 2011/99/UE, sobre la orden europea de protección (OEP), o la Directiva 2014/41/CE, relativa a la orden de investigación (OEI).

En efecto, la prevalencia del principio de la intergubernamentalidad en el ámbito de la OEDE constituye el fundamento de la opción del legislador europeo por un instrumento jurídico dotado de una mínima capacidad integradora, con la consecuencia inevitable de situar a la OEDE en un contexto donde su eficacia jurídica, como se ha descrito en el presente estudio, ha sido objeto de múltiples cuestionamientos.

El más reciente de ellos proviene de la Sentencia del Tribunal Constitucional Federal alemán de 15 de diciembre de 2015 (conocida por la doctrina como Solange III o Forever I), a la que el Tribunal de Justicia responde mediante la Sentencia de 5 de abril de 2016, Aranyosi-Căldăraru, tratando de 
mantener el control sobre la interpretación de los derechos fundamentales reconocidos en la Carta.

Con esta finalidad última, el Tribunal de Justicia articula, con carácter excepcional, un procedimiento en dos fases (denominado test Aranyosi) aplicable por la autoridad jurisdiccional de ejecución de una OEDE, a resultas del cual esta puede denegar la entrega, eludiendo la aplicación del principio del reconocimiento mutuo de las resoluciones judiciales, al margen de los supuestos «tasados» de no ejecución contemplados en la decisión marco sobre la OEDE.

Específicamente, la activación del test Aranyosi conlleva el nacimiento de una duda en la autoridad jurisdiccional de ejecución sobre si el grado de vulneración de un derecho fundamental por el Estado emisor resulta lo suficientemente grave para quebrar el principio de confianza recíproca, o, lo que es lo mismo, la sospecha de que el Estado emisor vulnera real y efectivamente los valores consagrados en el art. 2 TUE.

Una duda que nace en la autoridad jurisdiccional de ejecución y que el test Aranyosi está destinado a clarificar respecto de ella misma, de ahí que pueda estimarse que la articulación por el Tribunal de Justicia de este test supone la instauración del principio de "desconfianza recíproca» entre los Estados miembros en relación con el respeto de los valores comunes en los que se sustenta la Unión Europea.

En un primer momento se interpretó por la doctrina que las «circunstancias excepcionales» a las que el Tribunal de Justicia vinculaba la activación del test Aranyosi derivaban del carácter absoluto de la prohibición de la tortura y de las penas o tratos inhumanos y degradantes, pero, como vaticinara Ruiz (2017), su extensión en la Sentencia de 25 de julio de 2018 (Gran Sala), LM, respecto del derecho a un proceso equitativo, permite la aplicación de dicho test respecto de cualquier derecho fundamental, y convierte al art. 1.3 de la decisión marco sobre la OEDE en una excepción general de derechos fundamentales.

Pero, además, la activación de la primera fase del test Aranyosi implica la recopilación y la valoración por la autoridad jurisdiccional de ejecución $-\mathrm{y}$ no por las instituciones de la Unión según el procedimiento del art. 7 TUE-, de información genérica, en algunos supuestos, proveniente de documentos de fiabilidad dudosa, acerca del grado de cumplimiento de los derechos fundamentales por el Estado emisor que puedan acreditar deficiencias sistémicas o generalizadas. De ahí que coincidamos con Von Bogdandy et al. (2018) en la consideración de que resulta especialmente cuestionable que el Tribunal de Justicia haga recaer esta difícil tarea «sobre los hombros» del juez nacional.

De otro lado, podría entenderse que a través de la articulación del test Aranyosi el Tribunal de Justicia trata de aproximarse al sistema de garantía 
derivado del Convenio Europeo para la protección de los Derechos Humanos y las Libertades Fundamentales, pero entre ellos se aprecian diferencias sustanciales en tanto que este último se limita a la comprobación individual o concreta del respeto de los derechos reconocidos en el Convenio respecto de la persona cuya entrega es reclamada — verificación que equivale a la segunda fase del test Aranyosi- ${ }^{36}$.

En consecuencia, la metodología en el procedimiento de tutela de los derechos fundamentales incorporada en el test Aranyosi no solo dificulta su armonización con el sistema del Tribunal Europeo de Derechos Humanos, sino que tampoco resulta inocua respecto del grado de eficacia en la tutela de los derechos en el ámbito de la Unión. En efecto, como mantiene Callewaert (2018: 1700), en la protección de los derechos fundamentales la aproximación metodológica resulta muy importante, en la medida en que «derechos idénticos aplicados de acuerdo con diferentes metodologías» pueden dar lugar a diferentes grados de protección de los individuos.

En cualquier caso, ciertamente podría considerarse que las sentencias Aranyosi-Căldăraru y $L M$ constituyen el comienzo de un «largo viaje» que puede transitar por el camino de la creación de un mecanismo global de la Unión para la democracia, el Estado de derecho y los derechos fundamentales (democracy, rule of law and fundamental rights, DRF, en sus siglas en inglés), como el solicitado por el Parlamento Europeo en su Resolución de 25 de octubre de $2016^{37}$.

Un engranaje que, a modo de «sistema de monitorización», permitiera a la Unión Europea estar en condiciones de actuar a través de sus propios procedimientos legales, sin tener que esperar a que un retroceso en el Estado de derecho, una flagrante violación de los derechos humanos, u otras violaciones de los valores de la UE sean constatados por «actores externos» como Naciones Unidas, el Consejo de Europa (incluido el TEDH) o el Comité Europeo para la Prevención de la Tortura (Bárd y Van Ballegooij, 2018: 363).

Pero la apertura de esta senda no estaría exenta de riesgos, en tanto que, en última instancia, podría suponer la definitiva renuncia a dar cumplimiento por la UE al mandato contemplado en el art. 6.2 TUE, cuando, en opinión

36 Véanse, entre otras, las sentencias del TEDH Tarakhel $v$. Switzerland. Appication n. 29217/12, de 4 de noviembre de 2014, y Avotiňš v. Latvia. Application n. 17502/07, de 23 de mayo de 2016.

37 Mecanismo de la Unión para la democracia, el Estado de derecho y los derechos fundamentales. Resolución del Parlamento Europeo, de 25 de octubre de 2016, con recomendaciones destinadas a la Comisión sobre el establecimiento de un mecanismo de la Unión para la democracia, el Estado de derecho y los derechos fundamentales (2015/2254(INL)), P8_TA(2016)0409, Recomendación 1. 
de Callewaert (2018), la adhesión de la Unión Europea al Convenio Europeo de Derechos Humanos sigue siendo un objetivo a perseguir para «el entendimiento colectivo y el respeto de los derechos fundamentales como los hemos conocido en Europa desde hace casi 70 años».

\section{Bibliografía}

Alonso García, R. (2012). Sistema jurídico de la Unión Europea. Cizur Menor (Navarra): Civitas-Thomson Reuters.

Asp, P. (2005). Mutual recognition and the development of criminal law cooperation within the EU. En E. J. Husabø y A. Strandbakken (eds.). Harmonization of criminal law in Europe (pp. 23-40). Antwerpen: Intersentia.

Bantekas, I. (2007). The principle of mutual recognition in EU criminal law. European Law Review, 32 (3), 365-385.

Bapuly, B. (2009). European Arrest Warrant under Constitutional Attack. Vienna Online Journal on International Constitutional Law, 3 (1), 16-22.

Bárd, P. y Van Ballegooij, W. (2018). Judicial independence as a precondition for mutual trust? The CJEU in Minister for Justice and Equality v. LM. New Journal of European Criminal Law, 9 (3), 353-365.

Borgers, M. J. (2007). Implementing Framework Decisions. Common Market Law Review, 44 (5), 1361-1386.

Bustos Gisbert, R. (2016). ¿Un insuficiente paso en la dirección correcta? Comentario a la Sentencia del TJUE (Gran Sala), de 5 de abril de 2016, en los casos acumulados Pal Aranyosi (C-404/15) y Robert Caldararu (C-659/15 PPU). Revista General de Derecho Europeo, 40, 138-155.

Callewaert, J. (2018). Do we still need article 6(2) TEU? Considerations on the absence of EU accession to the ECHR and its consequences. Common Market Law Review, 55 (6), 1685-1716.

Canor, I. (2013). My brother's keper?...solange: 'An ever closer distrust among the peoples of Europe'. Common Market Law Review, 50 (2), 383-421.

De Vergottini, G. (2010). Más allá del diálogo entre tribunales. Comparación y relación entre jurisdicciones. Cizur Menor (Navarra): Civitas.

Denza, E. (2002). The Intergovernmental Pillars of the European Union. Oxford: Oxford University Press.

Fonseca Morillo, F. J. (2003). La orden de detención y entrega europea. Revista de Derecho Comunitario Europeo, 14, 69-95.

Geyer, F. (2008). European Arrest Warrant. Court of Justice of the European Communities. Judgment of 3 May 2007, Case C-303/05, Advocaten voor de Wereld VZW v. Leden van de Ministerraad. European Constitutional Law Review, 4, 149-161. 
Grasso, G. (2015). The Instruments of Harmonisation of National Criminal Law, Their Enforcement and the Role of the Court of Justice. New Journal of European Criminal Law, 6 (4), 494-504.

Hinarejos, A. (2006). Bundesverfassungsgericht (German Constitutional Court). Decision of 18 July 2005 (2 BvR 2236/04) on the German European Arrest Warrant Law. Common Market Law Review, 43, 583-595.

- (2008). On the Legal Effects of Framework Decisions and Decisions: Directly Applicable, Directly Effective, Self-executing, Supreme? European Law Journal, 14 (5), 620-634.

Hong, M. (2016). Human Dignity, Identity Review of the European Arrest Warrant and the Court of Justice as a Listener in the Dialogue of Courts: BVerfG 15 December 2015, 2 BvR 2735/14, Solange III, and ECJ (Grand Chamber) 5 April 2016, Joined Cases C-404/15 and C-659/15 PPU, Aranyosi and Caldararu. European Constitutional Law Review, 12 (3), 549-563.

Iglesias Sánchez, S. (2010). La jurisprudencia constitucional comparada sobre la orden europea de detención y entrega, y la naturaleza jurídica de los actos del Tercer Pilar. Revista de Derecho Comunitario Europeo, 35, 169-192.

Klimek, L. (2015). European Arrest Warrant. Cham: Springer International Publishing.

Komárek, J. (2007). European Constitutionalism and the European Arrest Warrant: In Search of the Limits of 'Contrapunctual Principles'. Common Market Law Review, 44, 9-40.

Kuijper, P. J. (2004). The Evolution of the Third Pillar from Maastricht to the European Constitution: Institutional Aspects. Common Market Law Review, 41 (2), 609-626.

Łazowski, A. (2005). Constitutional Tribunal on the Surrender of Polish Citizens Under the European Arrest Warrant. Decision of 27 April 2005. European Constitutional Law Review, 1, 569-581.

Lenaerts, K. (2017). La vie aprèsl'avis: Exploring the principle of mutual (yet not blind) trust. Common Market Law Review, 54 (3), 805-840.

Lenaerts, K. y Corthaut, T. (2006). Of Birds and Hedges: The Role of Primacy in Invoking Norms of EU Law. European Law Review, 31 (3), 287-315.

Mancano, L. (2018). Judicial Harmonisation through Autonomous Concepts of European Union Law: The Example of the European Arrest Warrant Framework Decision. European Law Review, 43 (1), 69-88.

Marguery, T. (2016). Rebuttal of Mutual Trust and Mutual Recognition in Criminal Matters: Is 'Exceptional' Enough? European Papers, 1 (3), 943-963.

Mathisen, G. (2010). Nordic Cooperation and the European Arrest Warrant: Intra-Nordic Extradition, the Nordic Arrest Warrant and Beyond. Nordic Journal of International Law, 79, 1-33.

Meyer, F. (2016). Case Notes: From Solange II to Forever I. The German Federal Constitutional Court and the European Arrest Warrant (and how the CJEU responded). New Journal of European Criminal Law, 7 (3), 277-294. 
Mitsilegas, V. (2015). The Symbiotic Relationship between Mutual Trust and Fundamental Rights in Europe's Area of Criminal Justice. New Journal of European Criminal Law, 6 (4), 457-480.

Muñoz de Morales Romero, M. (2017). Dime cómo son tus cárceles y ya veré yo si coopero: Los casos Caldararu y Aranyosi como nueva forma de entender el principio de reconocimiento mutuo. Indret: Revista para el Análisis del Derecho, 1, 1-26.

Nohlen, N. (2008). Germany: The European Arrest Warrant case. International Journal of Constitutional Law, 6, 153-161.

Nowag, J. (2016). EU law, constitutional identity, and human dignity: A toxic mix? Bundesverfassungsgericht: $M r$ R. Common Market Law Review, 53 (5), 1441 1454.

Nußberger, A. (2008). Poland: The Constitutional Tribunal on the implementation of the European Arrest Warrant. International Journal of Constitutional Law, 6, $162-170$.

Peers, S. (2004). Mutual Recognition and Criminal Law in the European Union: Has the Council got it wrong? Common Market Law Review, 41, 5-36.

- (2007). Salvation outside the Church: Judicial Protection in the Third Pillar after the Pupino and Segi Judgements. Common Market Law Review, 44, 883929.

Pollicino, O. (2008). European Arrest Warrant and Constitutional Principles of the Member States: a Case Law-Based Outline in the Attempt to Strike the Right Balance between Interacting Legal Systems. German Law Journal, 9 (10), 1313 1355.

Reding, V. (2010). The Future of European Criminal Justice under the Lisbon Treaty. Speech at the European Law Academy (SPEECH/10/89). Trier, 12 March, 1-8.

Reinbacher, T. y Wendel, M. (2016). Case Notes: The Bundesverfassungsgericht's European Arrest Warrant II Decision. Maastricht Journal of European and Comparative Law, 23 (4), 702-713.

Ruiz Yamuza, F.-G. (2017). ¿Réquiem por el principio de confianza mutua?: reconocimiento mutuo y tutela de derechos fundamentales en la jurisprudencia del TJUE a propósito de la Orden de Detención Europea. Revista General de Derecho Europeo, 43, 201-245.

Sarmiento, D. (2008). European Union: The European Arrest Warrant and the quest for constitutional coherence. International Journal of Constitutional Law, 6, 171-183.

- (2018). Editorial. A comment on the CJEU's judgment in LM. Maastricht Journal of European and Comparative Law, 25 (4), 2018, 385-387.

Spaventa, E. (2007). Opening Pandora's Box: Some Reflections on the Constitutional Effects of the Decision in Pupino. European Constitutional Law Review, 3, 5-24.

Tomuschat, Chr. (2006). Inconsistencies. The German Federal Constitutional Court on the European Arrest Warrant. European Constitutional Law Review, 2, 209226. 


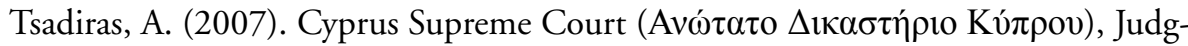
ment of 7 November 2005 (Civil Appeal no. 294/2005) on the Cypriot European Arrest Warrant Law. Common Market Law Review, 44, 1515-1528.

Van Sliedregt, E. (2007). The European Arrest Warrant: Between Trust, Democracy and the Rule of Law. European Constitutional Law Review, 3, 244-252.

Von Bogdandy, A., Bogdanowicz, P., Cannor, I., Schmidt, M. y Taborowski, M. (2018). Drawing Red Lines and Giving (Some) Bite-The CJEU's Deficiencies Judgment on the European Rule of Law. Verfassungsblog on Matters Constitutional. Disponible en: https://bit.ly/2r0q9pF.

Weyembergh, A. (2005). The Functions of Approximation of Penal Legislation within the European Union. Maastricht Journal of European and Comparative Law, 12 (2), 149-172.

Wyrozumska, A. (2004-2005). Some Comments on the Judgments of the Polish Constitutional Tribunal on the EU Accession Treaty and on the Implementation of the European Arrest Warrant. Polish Yearbook of International Law, 7-30.

Zemánek, J. (2007). The Emerging Czech Constitutional Doctrine of European Law. European Constitutional Law Review, 3 (3), 418-435. 